\title{
ENTRETIEN AVEC LE PROFESSEUR DR. LOUIS HÉBERT DU DEPARTEMENT DES LETTRES ET HUMANITÉS DE L'UNIVERSITÉ DU QUEBEC A RIMOUSKI (UQAR)
}

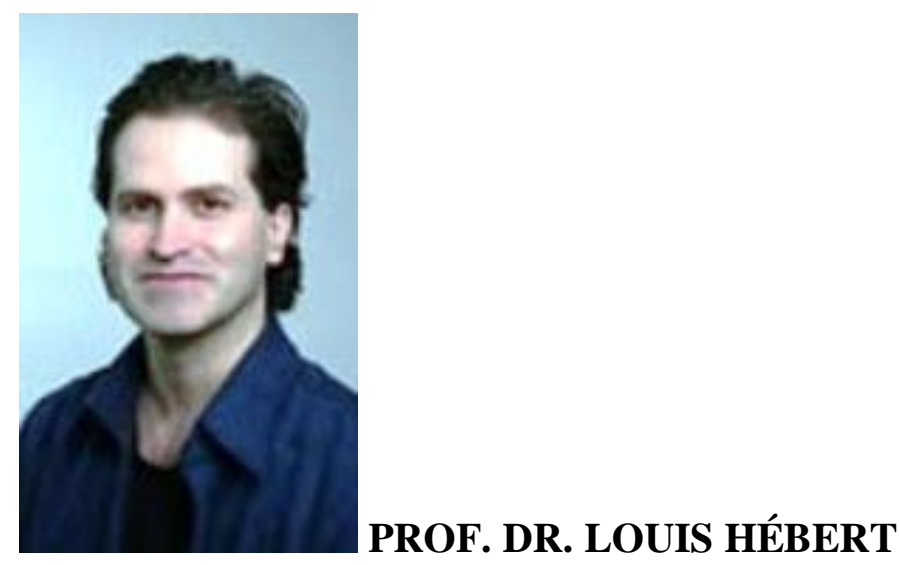

ASEL. Monsieur Louis Hébert, bonjour. Acta Semiotica et Lingvistica est honoré de nous avoir accordé cette interview. Pour commencer, pourriez-vous nous parler un peu de vous?

L.H. Je suis professeur au Département des lettres et humanités de l'Université du Québec à Rimouski (UQAR) depuis 1999. J'enseigne le théâtre, la poésie, la théorie et la création littéraires. Mes recherches portent principalement sur la sémiotique (textuelle et visuelle), la sémantique interprétative, la méthodologie de l'analyse littéraire, l'onomastique, Magritte, le bouddhisme.

J'ai écrit quelques œuvres: un recueil de poèmes-aphorismes d'un vers (Sagesse $d u$ loup, Art le sabord), des chansons, un recueil de nouvelles (dont trois des nouvelles ont été publiées: Art le sabord, 90, 94 et 96).

ASEL Super S'il vous plaît, pourriez-vous maintenant nous parler un peu de votre expérience professionnelle et scientifique?

L.H. Je suis né à Hauterive (maintenant Baie-Comeau), une petite ville du Québec (Canada). Vers l'âge de 20 ans, j'ai dû choisir entre la littérature et la philosophie. J'ai choisi la littérature. Après un baccalauréat en littérature à l'Université du Québec à Rimouski, j'ai poursuivi à la maîtrise dans le même domaine à l'Université du Québec à Montréal. Au moment de mon doctorat, la sémiotique - que j'avais rencontrée quelques années plus tôt - s'est imposée comme mon approche de prédilection. J'ai obtenu mon doctorat de l'Université Laval, avec une thèse sur l'analyse des noms 
propres dans les textes littéraires. Mon principal maître intellectuel est François Rastier. Le principe de François Rastier voulant que le global détermine le local (le genre détermine le texte, le texte détermine le sens des mots, etc.) nous oblige à étudier les systèmes culturels qui englobent les produits sémiotiques. Évidemment, on n'a pas à «terminer » une analyse «exhaustive» d'une culture donnée pour pouvoir légitimement commencer à analyser un produit sémiotique de cette culture. Mais il faut garder en tête que la structure de la culture impacte les produits qui en découlent. C'est pourquoi, à la typologie des systèmes de Rastier — dialecte, sociolecte, idiolecte —, j'ai proposé d'ajouter le culturolecte (le système de la culture) et même l'anthropolecte (le système qui sous-tend toutes les cultures humaines). Mais j'ai d'autres maitres intellectuels, comme Jean-Marie Klikenberg, Claude Zilberberg et Jacques Fontanille. Bien que je ne les ai pas vraiment rencontrés, je considère aussi Algirdas Julien Greimas et Joseph Courtés comme mes maîtres intellectuels également. Il est très courant au Québec que les professeurs de littérature produisent aussi des textes littéraires sans nécessairement être spécialisés en création littéraire (il y a des professeurs spécialisés dans ce champ).

ASEL. Quels sont les principaux travaux écrits et publiés?

L.H. En plus d'environ 80 articles et chapitres de collectifs, j'ai fait paraître: (1) An Introduction to Applied Semiotics (Abingdon, Routledge, sous presse); (2) Cours de sémiotique (Paris, Classiques Garnier, sous presse); (3) L'onomastique littéraire. Théorie et méthode pour les noms propres (Paris, Classiques Garnier, accepté, avec Éric Trudel); (4) L'analyse des textes littéraires: une méthodologie complète (Paris, Classiques Garnier); (5) Dispositifs pour l'analyse des textes et des images. Introduction à la sémiotique appliquée (Limoges, Presses de l'Université de Limoges, deuxième tirage) et (6) Introduction à la sémantique des textes (Paris, Honoré Champion, deuxième tirage). J'ai dirigé (7) Le plaisir des sens. Euphories et dysphories des signes (Québec, Presses de l'Université Laval) et codirigé, avec Lucie Guillemette, trois livres (Québec, Presses de l'Université Laval): (8) Signes des temps. Temps et temporalités des signes; (9) Intertextualité, interdiscursivité et intermédialité; (10) Performances et objets culturels. J'ai codirigé, avec Pascal Michelucci et Éric Trudel, (11) Magritte: perspectives nouvelles, nouveaux regards (Québec, Nota Bene). J'ai placé dans Internet un (12) Dictionnaire de sémiotique (http://www.signosemio.com/documents/dictionnaire-semiotique-generale.pdf). Sont en préparation les livres (13) Introduction à l'analyse des textes littéraires: 60 perspectives; (14) Sens de la transcendance. Sémiotique et spiritualité (Classiques 
Garnier, accepté, avec Étienne Pouliot, Éric Trudel et George Vasilakis, dir.); (15) Petits essais sur le bouddhisme tibétain.

Enfin, je suis directeur de (16) Signo - Site Internet bilingue de théories sémiotiques (www.signosemio.com; plus de 20.000 visites par mois) et (17) d'une base de données Internet sur la quasi-totalité des œuvres et thèmes de Magritte (www.magrittedb.com). Courriel: louis_hebert@uqar.ca. Orcid.org/0000-0002-8991-5316.

(ASEL) Quels projets scientifiques envisagez-vous pour l'avenir?

L. H. Actuellement, je suis en train de constituer une équipe de recherche sur Sémiotique et spiritualité. Nous voulons produire une demande de subvention à un organisme subventionnaire majeur en 2022. Dans ce cadre, je compte poursuivre et développer mes analyses du bouddhisme tibétain à l'aide de la sémiotique. Je coorganise un colloque international - mon $17^{\mathrm{e}}$ colloque organisé ou coorganisé - sur Sens de la transcendance. Sémiotique et spiritualité qui aura lieu à Québec en juin 2020. 